\title{
SOBRE LA RETÓRICA
}

\author{
Carlos PEREDA \\ Instituto de Investigaciones Filosóficas. UNAM-México
}

En este trabajo se tratará de distinguir entre una retórica virtuosa y una retórica viciosa. Para ello se atenderán los vínculos entre la retórica y la literatura por un lado, y aquellos entre la retórica, la argumentación y la política, por otro.

\section{I}

Apenas se recuerda que el arte de la retórica surge como una necesidad del convivir político de la democracia ateniense, se esboza ya la conexión entre retórica y vida pública no condicionada de antemano, no determinada por la autoridad absoluta de una tradición. Como Nietzsche señaló, la retórica es un "arte republicano" (otros tal vez elijan defender: la retórica es un "vicio republicano").

Esta primera conexión sugiere una más general entre retórica y vida pública o privada no condicionada de antemano, sino que busca orientarse por el poder de los buenos argumentos: entre retórica y sabiduría ilustrada. Tales conexiones no son difíciles de articular: si el poder público y privado, si la capacidad de orientar y de orientarse no son más propiedades de cierta tradición, sino propiedades que dependen del convencimiento producido por los buenos argumentos, el arte de la retórica en tanto arte de presentar argumentos para convencer contribuye a construir la autonomía personal. Disponemos, pues, de una primera propuesta sobre lo que es la retórica, o si se prefiere, de un primer uso de la palabra setórica»: 
1. La retórica es el arte de presentar los argumentos de manera tal que, convenciendo, produzcan asentimiento.

Previsiblemente, pronto se querrá el poder de los buenos argumentos, incluso cuando se carece de ellos. En relación con esta demanda, Platón nos cuenta que surgió la oferta de los sofistas, maestros viajeros que iban de ciudad en ciudad, enseñando por cierta paga, el arte de adornar las palabras con el fin de producir convencimiento (¿labor que han heredado nuestros periodistas y demás "comunicólogos»?). Topamos, entonces, con una segunda propuesta sobre lo que es la retórica, o si se prefiere, con un segundo uso de la palabra "retórica»:

\section{La retórica es el arte del adorno verbal.}

En ambas propuestas, la retórica se constituye como el arte que trabaja con una dimensión de todo lenguaje: la dimensión expresiva en relación con el interlocutor, el ajustarse del lenguaje para producir efectos en cierto auditorio. $\mathrm{O}$, como algunos tal vez preferirán decir: se opera con la dimensión pragmática o con el aspecto "fuerza" del signo lingüístico.

Hay que considerar ya una objeción: si el adorno verbal es un instrumento formal, neutral a los diversos contenidos, entonces, la retórica se convierte en un método indiferente a los conceptos de verdad y de bien. De este modo, cualquiera que se encuentre entrenado en tal método podrá inducir aquellas creencias que mejor convengan a sus intereses o pasiones, independientemente de que se trate de creencias verdaderas o de intereses y pasiones legítimas. Esa retórica, según el Gorgias. es en lo concerniente al alma lo que la culinaria en lo referente al cuerpo ${ }^{1}$.

De inmediato Platón aclara esa afirmación en el siguiente fragmento de diálogo: «Polo, Bien. ¿Qué es lo que dices?, ¿que la retórica es la adulación? Sócrates. He dicho que es una parte de la adulación»².

A esta retórica fraudulenta, engañosa, aduladora, Platón le opone en el Fedro, otra retórica en tanto: «arte de guiar el alma por el camino de los razo-

1 Gorgias 465 c, en PlaTon, Diálogos, Introducción de E. Lledó; Traducción y notas de J. Calonge Ruiz; Gredos, Madrid, 1982.

2 Gorgias 466 a, en op. cit. 
namientos, no sólo en los tribunales y en las asambleas populares sino también en las conversaciones privadas" ${ }^{3}$.

Es necesario, entonces, distinguir ya dos modalidades de tratar la dimensión expresiva del lenguaje y, con ello, de dirigirse a un auditorio: la retórica como arte de convencer y la retórica como método de seducir. Quien efectivamente se apoya en el poder de los buenos argumentos produce asentimiento, convenciendo. En cambio, produce asentimiento, seduciendo, quien sólo se respalda en los argumentos que le convienen, sean estos buenos, regulares o malos, sean pseudo-buenos argumentos o falacias, esto es, argumentos malos pero que parecen buenos.

Sin embargo, ¿existe realmente un contraste tan claro entre convencer y seducir? La respuesta sofista (de Grecia a los pos-modernos) fue - como en tantas ocasiones en que nos queremos defender - un ataque: se atacaron los conceptos de verdad y de bien en tanto conceptos objetivos o, al menos, en tanto conceptos con pretensión de validez intersubjetiva y capaces de ser respaldados argumentativamente. En relación con la verdad, se afirmó: ninguna creencia es verdadera o falsa en sí misma, puesto que no hay verdades independientes de alguna subjetividad; toda creencia en verdadera o falsa en relación con ciertos intereses o pasiones. Algo similar se indicó también de los otros valores, específicamente se propusieron los valores morales como un asunto de convención. La palabra "convención" se contrasta en este contexto con la palabra "naturaleza". Si las normas morales son asunto de convención y no de naturaleza, podríamos sacar como posible conclusión: dejemos tales convenciones a un lado y vivamos persiguiendo los propios intereses y pasiones, sin inhibiciones morales, propias de los débiles y los ineptos.

Sin embargo, ¿no nos conduce ese invitar al relativismo y hasta el escepticismo tanto empistémico como práctico? He aquí una tercera propuesta sobre lo que es la retórica, o si se prefiere, un tercer uso de la palabra "retórica":

3. La retórica es el método de producir asentimiento, seduciendo y, como tal, presupone un relativismo o incluso un escepticismo epistémico y/o práctico.

3 Fedro 261 a, en op. cit. 
En los debates sobre la retórica con frecuencia se confunden y hasta se funden estas propuestas como formando un entramado indisoluble. Sin embargo, creo que hay algunas interpretaciones de las propuestas 1 y 2 -la retórica como el arte de presentar con eficacia los argumentos en relación con un auditorio y la retórica como el arte del adorno verbal - que no implican, al menos que no implican de manera inevitable, la propuesta 3 - la retórica como el método de producir asentimiento a partir de ciertos intereses e independientemente de los conceptos de verdad y de bien-. Más todavía, sospecho que se puede defender cierta manera de interpretar positivamente los usos $1 \mathrm{y}$ 2 de la palabra «retórica» y atacar el uso 3 .

Atendamos rápidamente a la propuesta 2, o al uso 2 de la palabra "retórica»:

\subsection{La retórica es el arte del adorno verbal.}

O dicho de manera tal vez más apropiada: la retórica es el arte de usar las palabras de un modo bello, aptamente, con fuerza. Este uso de la palabra "retórica» anuncia ya sus efectos sobre la literatura. La influencia ha sido vasta y diversa. Se conoce que la decadencia de la oratoria pública en Roma hizo que el interés de los retóricos se dirigiera a la educación; así, el primer grupo de disciplinas que se debía cursar en la Edad Media estaba formado por el trivium de la retórica, la gramática y la lógica. En las clases de retórica, los alumnos analizaban y componían varios tipos de discursos siguiendo un orden que Cicerón resume como sigue: "el orador primero debe dirigirse a lo que quiere decir; luego conducir y organizar sus descubrimientos no meramente de una forma ordenada sino con ojo discriminador para sopesar... cada argumento; enseguida continua adornándolos con estilo; después tiene que memorizarlos; y finalmente, expresarlos en público con efecto y encanto" 4 .

Así, las "partes» del proceso retórico son: inventio o lo que se quiere decir, dispositivo o arreglo de las partes elocutio o estilo, memoria y pronuntiatio o

4 CiCERO, De oratore I 142, con traducción inglesa por E.W. Sutton, Harvard University Press, Boston, 1959. 
exposición oral. Junto a estas partes se codificó una serie de figuras del lenguaje (con nombres casi tan altisonantes como los del vocabulario de cierta lingüística contemporánea): catacresis, hipálage, sinécdoque, metonimia.... que el alumno, y también el poeta, debían dominar para llevar a cabo sus trabajos. De esta manera, la retórica clásica tenía un fuerte componente normativo; era una preceptiva y se centraba en la composición de discursos. Ambas pretensiones fueron atacadas y hasta eliminadas en los tiempos modernos y, específicamente, con el advenimiento de esa "escuela" de la imaginación centrífuga que fue el Romanticismo.

Con respecto a la primera pretensión, la normatividad, sospecho que el concepto de preceptiva juega en la tradición retórica un papel funcionalmente equivalente o casi, al concepto de metodología en la tradición científica moderna. En ambos casos, aparece una y otra vez la vana tentación del método - la metodolatría - en tanto búsqueda de criterios precisos, fijos y generales.

En relación con la segunda pretensión, la de constituir la retórica una metodología de la composición de discursos, en el Romanticismo se comenzó por razonar que lo que permitía al genio crear, permitía también al lector, al crítico, evaluar; muy pronto se acabó señalando que el genio no usa reglas para crear, sólo el lector, sólo el crítico necesita de ellas para analizar, para juzgar. La retórica se convierte, entonces, en algo así como una teoría de la eficacia literaria y hasta en una región de la crítica.

Sin embargo, la actitud romántica se extendió, a su vez, a la retórica en tanto recepción de la literatura, eliminando también allí toda normatividad en la composición; así, por ejemplo, de las cinco "partes» del proceso retórico sólo se conservarán las tres primeras -inventio, dispositio, elocutio- y ello, sin demasiadas pretensiones, simplemente como esquemas para describir y razonar la eficacia literaria, vagos marcos para organizar los itinerarios de la libertad: de la imaginación centrífuga.

Entonces ¿qué hacer hoy con la retórica en relación con la literatura y, en general con las artes? Por ejemplo, quien elogia hoy a un poeta o a un narrador porque posee una "buena retórica" (si es que se trata de un elogio), no implica con su afirmación que ese poeta o narrador cumple con cierto método, con ciertas reglas y figuras. Lo que se afirma es que ese poeta o narrador maneja eficazmente la dimensión expresiva del lenguaje, que es eficaz estéticamente para provocar estados de ánimo, pasiones, pensamiento, recuerdos, posibilidades del mundo y de la vida... A su vez, a partir del Romaticismo, el 
teórico de la literatura, el crítico, no tendrá ni que disponer de una metodología, ni necesariamente examinar si se cumple o no con ciertas reglas, o se usan o no ciertas figuras; podrá hacerlo o no, pero en el caso en que lo haga, se tratará de una tarea subordinada a la libre, a la imaginativa evaluación de si el texto en cuestión posee eficacia estética.

El inicial uso 2 de la palabra "retórica» puede, entonces, creo, comenzar a vertirse de manera más compartible como:

2.1. La retórica es el arte de producir y evaluar la eficacia estética.

\section{III}

Vayamos a la propuesta 1, o al uso 1 de la palabra «retórica»:

1.1. La retorica es el arte de presentar los argumentos de manera tal que, convenciendo, produzcan asentimiento.

Probablemente esta propuesta despierte mayores enconos que la anterior; en cualquier caso, éstos provienen de una actitud diferente. En el caso de la conjunción "literatura y retórica" la resistencias pertenecían a la tradición romántica; en cambio, con respecto a la conjunción «argumentación y retórica» las resistencias son parte de la tradición ilustrada.

Así, a partir de esa tradición muchos se han formulado dos clases de preguntas: ¿por qué necesitamos del arte de la retórica para producir asentimiento con buenos argumentos?, ¿acaso en nuestros convencimientos racionales intervienen también las pasiones? Y, por otra parte, ¿no basta acaso para convencer con disponer simplemente de buenos argumentos, «buenos argumentos" en el sentido de argumentos lógicamente válidos y con premisas verdaderas, esto es, "buenos argumentos» en lo que llamaré el sentido restringido de esa expresión?

Quién pregunta de la primera manera presupone una oposición radical entre la razón y las pasiones. Quien pregunta de la segunda manera defiende un concepto austero de razón, una razón fuerte, unitaria, casi diría, invulnerable, aunque limitada tanto teórica como prácticamente. Sin embargo, jes la razón humana esa razón? 
Para comenzar a discutir estas dudas daré un rodeo a través de dos dificultades: la vieja perplejidad de la akrasía o debilidad de la voluntad y el problema de la subdeterminación de muchos argumentos. El hecho de que ambas dificultades existan, si es que existen, parece contradecir algunas de las propuestas más queridas de la tradición ilustrada, al menos, contradice lo que llamaré la «propuesta socrática" y la "propuesta cartesiana". Pero, aunque estas propuestas son propuestas ilustradas, no agotan sin duda todo lo que se puede entender por Ilustración.

\section{a) La "propuesta socrática»}

Sócrates respondió la pregunta acerca de si basta para convencer con los "buenos argumentos" con una afirmativa enfática: quien conoce el bien lo realiza, quien hace el mal demuestra que está en el error; la razón práctica no es, así, más que una aplicación inevitable de la razón teórica. Aristóteles discute esta propuesta a lo largo del Libro VII de su Etica Nicomaquea. Señala Arisitóteles: "Cosa sorprendente sería, como pensaba Sócrates, que algún otro principio domine el conocimiento existente en el sujeto y que lo arrastre en torno de sí como a un esclavo. Sócrates combatía esta idea, sosteniendo por su parte que la incontinencia no existe, ya que nadie a sabiendas puede apartarse en su conducta de lo mejor, sino por ignorancia. Esta teoría, sin embargo, está manifiestamente en desacuerdo con los hechos observados» 5 .

"Hechos observados»: con frecuencia un agente actúa intencionalmente en contra de su propio buen juicio, sosteniendo que una acción es la mejor - por una razón- $-y$, no obstante, actuando de otra manera - también por alguna razón, aunque de menor fuerza que la razón anterior-. Este agente es un incontinente: un akratés. Así, una persona que posee, como se dice, «debilidad de la voluntad": a) actúa intencionalmente, b) juzga que sería mejor hacer $x$ que $y \mathrm{y} \mathrm{c}$ ) hace $y$ Ejemplo 1: El jefe de una oficina procura actuar con justicia; en relación con una vacante que se ha producido; se presentan dos candidatos, un desconocido y un amigo suyo que posee menos méritos para ocupar su cargo que el desconocido. El jefe piensa que, en justicia, le debería dar el cargo al desconocido; sin embargo, se lo da a su amigo.

5 ARISTÓTEles, Ética Nicomaquea, Versión de Antonio Gómez Robledo, Universidad Nacional Autónoma de México, México, 1983. 
Los ejemplos más relevantes de "debilidad de la voluntad" son aquellos que, como este primer ejemplo, poseen una dimensión moral: una persona cree que cierta acción es moralmente la mejor, lo que debe hacer y, no obstante, actúa de otro modo. A pesar de la familiaridad de las acciones de esta clase, de conocer lo que se debe hacer y de no hacerlo, hay una amplia "resistencia socrática" que no admite estos "hechos". Pues ¿̨cómo una persona puede actuar contra su propio juicio? La respuesta de Aristóteles es la siguiente: «Es claro, por tanto, que de los incontinentes debe decirse que están en una disposición análoga a la del dormido, el loco, o el borracho. El que tales hombres puedan hablar el lenguaje del conocimiento moral, no prueba que lo posean, pues aun los que están en los estados mencionados dan demostraciones científicas y recitan versos de Empédocles y los que empiezan a aprender una ciencia encadenan bien sus proposiciones, pero no la saben aún, pues para ésto hay que haberse connaturalizado con ella, y esto pide tiempon' 6 .

Para Aristóteles, la pasión, el deseo o el placer interfieren en nuestra capacidad de conocer y evaluar como lo hacen el sueńo, la locura o la ebriedad..... produciendo un pseudo-conocer, un pseudo-evaluar que es el conocer y el evaluar del incontinente. ¿Cómo suprimir la interferencia entre el evaluar moral del jefe en nuestro ejemplo 1 y su actuar? En general: ¿cómo eliminar la fragmentación entre teoría y praxis?, ¿cómo recuperar la unidad perdida entre razón teórica y razón práctica? $\mathrm{O}$, más en particular, ¿¿cómo hacer que el incontinente «escuche» su buen juicio?

Para responder a preguntas como éstas, la tradición aristotélica invita a estudiar las emociones, las pasiones, como parte decisiva del entrenamiento retórico. En este sentido, Aristóteles aceptó de la teoría retórica como una autorizada "base de datos" y hasta de elucidaciones sobre las emociones que permaneció válida en toda la tradición (hasta que Descartes propuso un acercamiento "científico" al asunto, pero cambiando sólo de retórica; sustantivamente el tratamiento permanece más o menos el mismo). Cicerón forma parte todavía de la tradición aristotélica cuando señala quizá no sin exageración: «No hay nada que sea tan potente sobre las emociones humanas como un discurso bien ordenado y embellecido" ${ }^{7}$.

6 Ética Nicomaquea 114720 , op. cit.

7 CICERÓN, Bruto 193, Introducción, versión y nota de Juan Antonio Ayala, Universidad Autónoma de México, México, 1966. 
Tenemos, entonces, que las mejores razones que posee el débil, el incontinente no lo motivan suficientemente; sus verdades y valores no se le presentan a su voluntad de la manera correcta, eficaz. Diremos, pues, que el discurso que el incontinente se dirige a sí mismo o que eventualmente otros le dirigen (maestros, políticos, sacerdotes, psicoterapeutas, periodistas, locutores de televisión....), no posee la retórica adecuada, la fuerza requerida.

Así, el discurso de la razón le resulta al incontinente, demasiado pálido en el sentido de "demasiado inconvicente" en relación con las voces de la pasión, del deseo, del placer. Por eso, en ese juego de voces que es cada persona, el discurso de la razón tiene que articularse con una retórica tan apropiada en relación con el interlocutor a que se dirige como las que articulan a la pasión, al deseo o al placer. Por ejemplo, el jefe de nuestro ejemplo 1 debería aprender que las razones morales le resulten tan fuertes como el deseo que su amigo progrese o el placer de tenerlo cerca. Hace falta un discurso de la razón práctica eficaz, capaz de «mover" la voluntad, conmoviendo, a la vez, la imaginación, las emociones, el entendimiento.

Pero para ello no hay ningún método, en el sentido de un conjunto de reglas precisas y generales; más bien, se necesita disponer de habilidades retóricas, conformadoras de la "imaginación ética", de nuestra "educación sentimental», del discernimiento moral.

Por supuesto, aceptar que la retórica en muchos casos posee fuerza motivacional y que con frecuencia aumenta la fuerza motivacional de los juicios y evaluaciones morales no implica sucumbir en el vértigo simplificador de afirmar que, por ejemplo, el problema de la debilidad de la voluntad se reduce a un problema de astucia retórica. Casos extremos de debilidad de la voluntad - si es que todavía lo son-, como un adicto a las drogas o un glotón cumpulsivo que, sin embargo, en sus momentos de lucidez reconocen lo negativo de sus respectivos haceres, probablemente serán, en gran parte al menos, sordos a la mejor retórica. Sin embargo, si en estos casos se entiende por "mejor retórica" la «retórica terapéuticamente más apropiada», fuera de la retórica ¿disponemos acaso de muchas otras posibilidades?

Aceptando estas consideraciones, o al menos, algunas de ellas como la necesidad de ajustar retóricamente nuestros argumentos en relación con el auditoria a quien se dirigen, es posible indicar que la fundación de la retórica no se reduce al arte de la producción y evaluación de la eficacia estética. Podemos, pues, especificar la formulación 1.0 , señalando: 


\subsection{La retórica es el arte de la eficacia argumental práctica en relación con cierto auditorio.}

Con respecto a la argumentación práctica, la dimensión retórica del lenguaje establece, entonces, un "mediación" entre mucha teoría y mucha praxis: es un modo en que la teoría se vuelve actuante. Después de todo, para cumplir parte de esta función surgió el arte de la retórica en la democracia ateniense. No obstante, ni siquiera con ella se agota el ámbito de la retórica. ¿Qué es lo que nos falta?

\section{b) La «propuesta cartesiana»}

Una y otra vez, Descartes aconsejó -en el Discurso del Método, en la Primera Meditación - tener por falso todo lo que no fuese necesariamente verdadero $y$, por lo tanto, tener por falso incluso aquello que fuese probable o verosímilmente verdadero. De ahí que por argumentar Descartes entienda la acción de respaldar cierto enunciado en otros enunciados, reduciendo el concepto de respaldo a un "respaldo deductivo", a un "respaldo determinado". Pero ¿qué otras clases de respaldos hay — si es que los hay — fuera del respaldo determinado?

Por ejemplo, en la vida cotidiana y en el razonar científico, disponemos de respaldos inductivos. La expresión "respaldos inductivos" o simplemente, la palabra "inducción" suelen usarse tanto en un sentido amplio como en uno restringido. En su sentido amplio, se parte de que todos los argumentos son deductivos o inductivos, por lo tanto, «inductivo" es otra palabra para nodeductivo. En cambio, en su sentido restringido, las palabras «deductivo» $\mathrm{e}$ "inductivo" son predicados contrarios, no contradictorios como en su sentido amplio $y$, así, la inducción en sentido restringido o inducción enumerativa se convierte en uno de los muchos respaldos no deductivos, a saber, aquel respaldo que forma parte de un argumento: a) cuyas premisas y conclusión son enunciados empíricos, b) la conclusión no está deductivamente contenida en las premisas, $\mathrm{c}$ ) se presupone que continuarán las regularidades presentadas o implícitas en las premisas. Cualquier respaldo inductivo se encuentra, pues, "subdeterminado"; estamos ante un argumento que da un salto: la razonabilidad de este respaldo depende de la razonabilidad del salto. Por eso, a diferencia de un respaldo deductivo que es válido o inválido, una inducción y, en 
general, cualquier respaldo no deductivo tendrá diferentes grados de validez, o lo que es lo mismo, un argumento no deductivo puede ser más o menos malo, más o menos regular, más o menos bueno. Compárese estos ejemplos:

2: a) Según la historia, todos los días hasta hoy ha salido el sol. Por lo tanto, b) Mañana saldrá el sol.

3: a) Conocí una vez a un mexicano muy haragán. Por lo tanto, b) En México sólo habita gente muy haragana.

Los ejemplos 2 y 3 son inducciones enumerativas. El ejemplo 2 - ipese a Hume?- - es un buen argumento ya que los respaldos enunciados en a) son extensos. En cambio, el ejemplo 3 es malísimo, pues no se puede generalizar a un todo país una experiencia casualmente personal.

Cuidado, la comparación entre los ejemplos 2 y 3 puede hacernos sucumbir a un vértigo simplificador: creer que hay algún método cuantitativo para medir sin más los grados de validez de un argumento inductivo, creer que la diferencia entre una buena y una mala inducción depende exclusivamente de la cantidad de individuos examinados. Este no es el caso. Por ejemplo, si se consideran dos o tres tigres, podrá concluirse, muy razonablemente, generalidades acerca de la anatomía del tigre; por el contrario, si se estudia la historia de dos o tres ciudades españolas, sería insensato querer sacar alguna conclusión general acerca de la historia de las ciudades españolas. Con la palabra «tigre» designamos una clase natural y, por lo tanto, homogénea, por eso, se presumen ciertas uniformidades entre los ejemplares de esa clase. En cambio, la expresión "ciudades españolas" no designa ninguna clase natural, sino una "clalse cultural", históricamente constituida y muy heterogénea.

Así, en cada inducción enumerativa hay que discernir en qué medida los casos examinados representan los no examinados con respecto a la propiedad que se considera; al respecto, es particularmente difícil aprender a estar alerta en contra de ciertos vértigos argumentales, cuyo resultado es la eliminación de casos que hablan en contra de la inducción propuesta. Estas varias tareas no son fáciles puesto que no se dispone de un método estricto. Lo que se exige son frecuentes balances de diversas consideraciones para evaluar la subdeterminación en cuestión; se pide la intervención interna de la capacidad de juzgar.

Sospecho que la situación es general para todo argumento no deductivo. Consideremos todavía otro caso, los argumentos por analogía: se trata de argu- 
mentos que sacan una conclusión sobre un fenómeno, el analogado, comparándolo con otro real o ficticio, el análogo. Toda analogía se basa en la regla de consistencia: hay que tratar en los casos similares de manera similar. Por ejemplo, consideremos el siguiente pasaje: El alcohólico es tan culpable como quien ha contraido paperas o sufrido un infarto, en ambos casos, se trata de enfermos. Por lo tanto, si en el segundo caso nos se persigue a la persona enferma, tampoco debe hacérselo en el primer caso.

La analogía, de la cual depende este argumento, puede ser reconstruida como sigue. Ejemplo 4:

a) Análogo

Nadie es responsable de contraer paperas o de sufrir infartos.

Las paperas y los infartos son enfermedades.

No se persigue a gente que posee una enfermedad que no estaba en su responsabilidad evitar.

b) Analogado

Nadie es responsable de volverse alcohólico.

El alcoholismo es una enfermedad.

No se persigue a gente que posee una enfermedad que no estaba en su responsabilidad evitar.

c) Conclusión

No se debe perseguir a los alcohólicos.

Independientemente de que estemos de acuerdo con la conclusión ¿̨de qué manera podemos juzgar este cuarto ejemplo? En parte al menos, depende del interés que se tenga. Como en cualquier argumento por analogía, la dificultad radica en hacer un balance de consideraciones sobre la verdad de las afirmaciones explícitas o implícitas y sobre las semejanzas y diferencias relevantes entre el análogo y el analogado. Por ejemplo, ¿̧hasta dónde es verdad la afirmación "nadie es responsable de volverse alcohólico»? Defender tal cosa ¿̨no es quizá usar la palabra «responsabilidad» de manera un tanto extravagante? En cualquier casos, al contraer paperas o sufrir un infarto se es responsable - si se es responsable en algún sentido- de muy diferente modo a como se lo es en relación con el alcoholismo. Por otra parte, quien contrae paperas o sufre un 
infarto está enfermo, también en un sentido diferente al sentido en que lo está el alcohólico.

Con respecto a este cuarto ejemplo hay que balancear estas y otras consideraciones similares y, como en cualquier argumento por analogía, es importante discernir hasta dónde la consistencia obliga a asentir a la analogía trazada. Entonces, como en relación a los argumentos 2 y 3, también el argumento 4 está subdeterminado y para sopesarlo hay que apelar a la intervención interna de la capacidad de juzgar.

Pero ¿qué es eso de "intervención interna de la capacidad de juzgar»? Entiendo por «intervención externa de la capacidad de juzgar» cuando el juicio interviene con respecto al marco en que se lleva a cabo la argumentación y no en relación a la argumentación misma, ya que esta se encuentra determinada. Por ejemplo, se puede juzgar si es correcto aceptar la regla "los autos deben circular por la derechan; no obstante, una vez aceptada esta regla, frente a cualquier situación concreta, digamos, un policía, tendrá que hacer un uso elemental del esquema regla-caso y deducir; y, claro, su capacidad de juzgar no tendrá nada que hacer en el interior de esta deducción, pues nos encontramos frente a un argumento determinado. Por el contrario, entiendo por «intervención interna de la capacidad de juzgar" cuando el juicio, a la vez, examina el marco de la discusión e interviene en la argumentación misma, sopesando, llevando a cabo un balance de consideraciones, puesto que el argumento está subdeterminado, como es el caso de los argumentos en los ejemplos 2,3 y 4 y, en general, en cualquier argumento no deductivo. En este sentido, toda intervención interna de la capacidad de juzgar posee una dimensión retórica: el resultado de cualquier balance de consideraciones dependerá también, en alguna medida, de cómo se presenten estas consideraciones. Lo que es otra manera de decir: el resultado de cualquier balance de consideraciones a que obliga la subdeterminación de todos los argumentos no deductivos, depende también, en alguna medida, de la habilidad retórica.

Sin embargo las "resistencias cartesianas», no son menores que las «resistencias socráticas»: ¿es realmente necesario aceptar los peligros de la argumentación subdeterminada y con ello, la importancia teórica, epistémica de la dimensión retórica del argumentar? Lo es. Recuérdese, por ejemplo, que en derecho y en moral la mayoría de nuestras argumentaciones se encuentran subdeterminadas. Al respecto, retomemos el argumento 4, que posee tanto una dimensión jurídica como una moral. ¿Qué decir de esa analogía desde ambas 
dimensiones? Por lo pronto, desde el punto de vista jurídico habrá muchas situaciones en que la analogía resulte inaceptable. Lo habitual y lo justo es que un juez no trate de la misma manera a un conductor que provoca un accidente de tránsito porque maneja en estado de ebriedad que a un conductor que provoca un accidente de tránsito porque sufrió un infarto. Sin embargo, habrá otras situaciones en las que un juez podrá señalar que el alcoholismo es también una enfermedad, análoga a otras enfermedades. Cualquiera sea la posición sel juez, la fuerza de su analogía dependerá, en alguna medida, de su capacidad retórica.

Sin embargo, se insistirá "cartesianemente»: ¿tiene un juez que correr las aventuras que acechan en cualquier analogía? Sin duda, la analogía, o como se suele decir en derecho, el argumentum a simili o a pari, es uno de los medios para resolver uno de los problemas más decisivos del derecho: mediante el recurso a la analogía se adecua un sistema de normas fijas a un medio social impredecible y en constante transformación. En el párrafo anterior, el verbo "adecuar" creo que no es lo suficientemente abarcador: un argumentum a simili puede también extender el ámbito de vigencia de una norma jurídica a casos no previstos en la misma y hasta puede reinterpretarla a la luz de observaciones en torno al analogado. Más todavía, en general, hay un componente analógico en la mayoría de las aplicaciones que llevamos a cabo de un gran número de nuestras reglas, y ello no sólo vale con respecto a las reglas de derecho o de moral, sino en relación con todas las reglas. Se conoce: las situaciones no se repiten con exactitud; incluso las situaciones más tipificadas poseen variaciones y una regla tiene que, por definición, regular situacioness con cierto grado de variación, a veces, como en el caso de las reglas morales, con un grado muy grande de variación. Responder con consistencia a estas variaciones, lo que en muchos casos, como en la moral y el derecho, implica, responder con justicia, exige a menudo un laborioso trabajo analógico, con sus inevitables dimensiones retóricas. Consideraciones paralelas pueden realizarse en relación con la mayoría de los argumentos no deductivos, ésto es, con la mayoría de los argumentos subdeterminados en donde la capacidad de juzgar interviene de manera interna.

Si se aceptan, por lo menos algunas de estas consideraciones hay, pues, que ampliar de nuevo el ámbito de la retórica, no se trata sólo de un instrumento de eficacia argumental práctica, también:

1.2. La retórica es el arte de la eficacia argumental teórica, epistémica. 


\section{IV}

Examinemos, finalmente, la propuesta 3, o el uso 3 de la palabra "retórica»:

La retórica es el método de producir asentimiento, seduciendo y, como tal, presupone un relativismo o incluso un escepticismo epistémico y/o práctico.

Tal vez se proteste: ¿por qué no se empezó por discutir esta propuesta, en lugar de dar un "rodeo de tibieza" por las propuestas 1 y 2 ? En efecto, la propuesta 3 retoma de lleno la vieja polémica de Platón con los sofistas, la retórica como "mera" retórica, como "arte del engaño", como propaganda irresponsable. Hasta el momento, ¿no parece la discusión haberse "escapado por la tangente»?, ¿no se ha defendido una idea inocua de retórica, el arte de la eficacia estética o argumental, el modo estético o argumental de tratar la dimensión expresiva del lenguaje? Así - se agregará- se evita confrontarnos con la retórica como La Pérfida, La Confundente y hasta La Meretriz, la disciplina perversa del trivium de la retórica, la gramática y la lógica.

No nos alarmemos demasiado por tales propuestas; más bien, vayamos paso a paso. Por lo pronto, en la propuesta 3 quiero discutir tres dificultades: la primera en torno a la palabra "método», la segunda sobre el alarmante verbo "seducir», la tercera en relación con las no menos alarmantes palabras «relativismo" y "escepticismo".

En primer lugar, empiezo atendiendo la sustitución en la propuesta 3 de la palabra "método" por la palabra "arte" usada en las propuestas 1 y 2 , y en sus especificaciones 1.1, 1.2 y 2.1. En la discusión de estas propuestas se reconoce la presencia de la dimensión expresiva del lenguaje y del arte de operar con esa dimensión de manera tanto estética como argumental. Pero es muy distinto: a) reconocer la existencia de la dimensión expresiva del lenguaje y de las artes que tratan esa dimensión, que b) afirmar que hay algo así como una preceptiva retórica, que la retórica es un método que se puede aprender y usar independientemente del asunto en cuestión.

Al contraponer a) a b) resulta la oposición «arte de la retórica» versus «método de la retórica». ¿Qué decir de esta oposición? El concepto de arte remite a un saber práctico, al arte de hacer bien una cosa, al "saber cómo" (al knowing how) en relación con la materia concreta que se trabaja; y no hay un saber hacer en general, sólo uno relativo a la materia trabajada. Además, estamos 
ante una indisoluble unidad entre forma y contenido, tanto en lo que se refiere al arte del artesano como al del artista. Por otra parte, el sujeto de un arte es la primera persona: en todo arte se articula un saber hacer personal, e incluso, como en el caso del artista, hasta idiosincrático, que maneja, a la vez, formas y contenidos.

Por el contrario, el concepto de método implica, cierto saber teórico, un saber en qué consiste el método. También exige la distinción radical entre forma y contenido: poseer un método es disponer de una herramienta formal, de un conjunto de criterios precisos, fijos y generales, independientes de los contenidos a que se aplican. Por eso, el sujeto que dispone de un método es la tercera persona.

En relación con la retórica, como en tantos otros contextos de debate, gran parte de lo que implica la idea de métodos, específicamente, la distinción entre forma y contenido y la postulación de un sujeto impersonal, conducen por mal camino.

Respecto de la literatura, la propuesta de una preceptiva de escribir bien, la codificación de cierto conjunto de pasos y de reglas para producir un texto admirable, ésto es, estéticamente eficaz, descansa en una ilusión, o más bien, en varias ilusiones. Por un lado, no existe $e l$ texto admirable, no existe la eficacia estética; un texto puede ser estéticamente eficaz de muchas maneras y por diferentes razones, a veces incluso de maneras contradictorias y por razones contradictorias. No sorprenderá, entonces, que las técnicas para lograr eficacia estética también sean múltiples y hasta contradictorias. Por ejemplo, se aconseja escribir con oraciones cortas, lo que no impide que un texto que maneje con elegancia oraciones largas suela resultar infinitamente preferible a una prosa estilo telegrama. Esta observación trivial es generalizable: no hay regla de estilo más o menos válida, cuya regla opuesta y hasta contradictoria no sea también válida en algún contexto; el estilo es un asunto personal. Por eso, sigue vigente la vieja lección escolar de que no hay otro «método" para aprender a escribir que leer lo que está bien escrito y probar uno mismo escribir; no hay otro "método" para escribir bien que el "socializarse en la buena escritura». Algo similar hay que decir de la lectura y la crítica literaria: pensar que en las reglas y figuras de alguna tradición retórica pudiéramos encontrar un método a aplicar más o menos mecánicamente para producir lecturas o críticas es, de nuevo, ilusorio. Después del Romanticismo, lo que encontramos en las tradiciones retóricas, cuando lo encontramos, son materiales y técnicas a tener en 
cuenta por nuestro juicio para alimentar, organizar, provocar, articular.... las lecturas o críticas. Nada más, nada menos.

Consideraciones paralelas deben hacerse con respecto a la eficacia argumental. Argumentar con eficacia práctica es un arte tan sutil, tan esquivo, tan poco codificable como producir o evaluar eficacia estética. En ambos casos se trata, ante todo, de un saber práctico personal, de un saber hacer que de caso en caso se apoya en diferentes y variables saberes proposicionales, a menudo no explícitos.

La situación es todavía más clara con la eficacia argumental teórica, epistémica, con el poder teórico de los buenos argumentos. No es posible presentar ningún argumento de manera tal que, convenciendo, produzca asentimiento, si se ignora el asunto de que trata ese argumento; sin embargo, dicha consideración es particularmente válida en relación con la eficacia argumental teórica. Más todavía, tiendo a pensar que en relación con la eficacia argumental teórica la "propuesta socrática" posee en alguna medida, parte de razón. Nadie duda que tenderá a argumentar teóricamente mejor sobre un problema quien más sepa acerca de ese problema. Por ejemplo, sólo un buen biólogo o un buen jurista podrá hacer buenas inducciones o buenas analogías en biología o en derecho. Incluso me inclinaría a pensar que forma parte del concepto de ser un buen biólogo o un buen jurista tener la capacidad de formular, entre otras argumentaciones, buenas inducciones y buenas analogías en sus respectivos campos.

Entonces, la palabra "retórica», después del Romanticismo, no puede, no debe designar un método sino varias técnicas, un saber hacer personal que hay que aprender en relación con cada asunto específico; en ningún casos, se puede defender la existencia de una preceptiva formal aplicable por doquier de manera más o menos mecánica e independientemente del asunto que se está debatiendo.

En segundo lugar, quiero discutir en relación con la propuesta 3 la dificultad que expresa la frase "la retórica como seducción". El verbo "seducir» se usa en el sentido de: cautivar, encantar, fascinar, embelesar..., y todo ello, con un toque negativo, sugiriéndose que se trata de un hechizar, embaucar, embobar. Por eso, cuando hablamos de una seducción, solemos pensar en un engaño con maña, un empujar sutil, un persuadir suavemente al mal. De ahí la vieja sospecha platónica en contra de la retórica: la retórica como un mover el ánimo sin razones para imponer ciertos intereses o pasiones. ¿Qué decir de este ataque? 
Sin duda, la dimensión expresiva del lenguaje es peligrosa, aunque no más peligrosa que la dimensión informativa. Además, en ese sentido casi "todo" es peligroso: también son peligrosas las cacerolas, pues con una cacerola se puede cocinar sopa o partirla a un amigo la cabeza y, no por ello, nos apartamos de las cacerolas, incluso "corremos el peligro" de tenerlas a nuestro alrededor. Por otra parte, en el caso de la dimensión expresiva se trata de un aspecto inevitable de cualquier lenguaje; entonces, ¿qué hacer? Como es inútil combatir la dimensión expresiva hay que, más bien, usar con legitimidad el arte de su eficacia, tanto estética como argumental, tal como se propone en nuestra discusión de las propuestas 1.1, 2.1 y 2.2. Se trata, pues, de presentar los buenos argumentos de manera tal que, convenciendo, produzcan asentimiento -eficacia argumental- o de usar las palabras con fuerza, con imaginación centrífuga - eficacia estética-.

No obstante, con facilidad sucumbe al vértigo de lo sublime ${ }^{8}$-pone "los ojos en blanco" e ignora las dificultades más a la vista - quien no toma en serio la provocación que conllevan palabras como "seducción" en la propuesta 3. De esta manera, se descuida la ambigüedad de todo arte retórico: se descuida la ambigüedad de todo cautivar, encantar, fascinar, embelesar... Así, en lo que respecta a la eficacia argumental, hay que subrayar la inseguridad extremadamente comprometedora de muchos argumentos subdeterminados. Por ejemplo, de la mano de inducciones enumerativas como los argumentos del tipo C - «conocí a un mexicano muy haragán, por lo tanto, en México...»con retórica inspiradora, con propaganda bien dirigida podrían encenderse los ánimos en contra de cierto grupo o de cierto país hasta provocar actos de crueldad y hasta una abierta violencia. De ahí los riesgos de los argumentos tipo $\mathrm{C}$ o "argumentos anecdóticos" como fuente de esquemas cognitivos distorsionadores, como matriz de estereotipos y prejuicios sociales: argumentos que, a partir de una situación particularísima, pretenden describir un estado de cosas general, y sólo hechizan, embaucan, emboban....., entregando creencias falsas, resultado de información incompleta y juicios de valor injustificados. En general, he aquí algunos riesgos de cualquier retórica.

En tercer lugar, consideremos todavía en relación con la propuesta 3, la dificultad aludida con palabras como "relativismo" y "escepticismo". Tal vez

8 Cf. C. PeredA, Vértigos argumentales. Una ética de la disputa, Anthropos, Barcelona, 1994, págs. 225-260. 
algunas doctrinas defendidas por los sofistas, o al menos, por la tradición retórica, presuponen la idea de un "método de la retórica" y conducen a una relativismo epistémico y/o práctico. Sin embargo, lo que en esta discusión interesa preguntar es: ¿lo dicho para defender nuestra interpretación de las propuestas 1 y 2 sobre la retórica posee también tales consecuencias? Es probable que la retórica en tanto arte de la eficacia literaria sea indiferente tanto al problema del relativismo como al del escepticismo, salvo cuando, como en el caso de una tradición retórica a la manera del deconstruccionismo, se elimina toda tipología de textos y de lecturas y se propone un tipo de lectura, la lectura literaria, como la lectura en general. Para quien se incline por esta decisión, las lecturas resultantes, y ello sucede con frecuencia cuando no se quiere distinguir, tenderán a la monotonía o simplemente, al tedio. ¿Alguien entiende mejor la Crítica de la razón pura teniendo en cuenta sus pobres metáforas? Sucumbir al vértigo simplificador ${ }^{9} \mathrm{y}$ reducir un texto con ambición directa de verdad argumentada como la Crítica a sus expresiones laterales, más que signo de escepticismo, es signo de incomprensión. $O$ si se prefiere, de ceguera; por aquello de que un ojo que no distingue es un ojo que no ve.

Más complicado es el caso en relación con la propuesta 1 en torno al poder de los buenos argumentos. Tanto con respecto a la eficacia argumental práctica como en relación con la eficacia argumental teórica parecería que es necesario introducir una variable de relatividad como es el contexto argumental, con todo lo que ello implica. En lo que atañe a la eficacia argumental práctica este contexto puede ser incluso tan concreto como cuando una persona incontinente presenta su conflicto a un terapeuta. Sin embargo ¿qué tiene que ver con el relativismo, y mucho menos con el escepticismo, el hecho de que existan situaciones particulares? Algo similar podría preguntarse en relación con la eficacia argumental teórica: el hecho de que haya que razonar de caso en caso si una inducción enumerativa o una analogía son correctas, no hace de esos argumentos respaldos al relativismo.

¿Qué queda, pues, de la retórica, después de la Ilustración y el Romanticismo? En primera lugar, reconstructivamente, debemos preservar el

9 Cf. Vértigos argumentales, págs. 137-168. 
estudio de las tradiciones retóricas del pasado, de sus logros y de sus ilusiones y, de manera más constructiva, es prometedor entrenarse en el arte de ocuparse con la eficacia estética y la eficacia argumental de la dimensión expresiva de todo lenguaje, tanto para producir esas eficacias en relación con un interlocutor, como para evaluarlas. En segundo lugar, hay que reconocer que la dimensión expresiva del lenguaje y las artes de tratarla son, como ya lo advirtió Platón, ambiguas: método para adular o arte para guiar el alma. Por lo tanto, estamos frente a dimensiosnes turbulentas, frente a disciplinas peligrosas, que incluyen desde la retórica cautivadora de un Dante o de un Wittgenstein hasta las propagandas - religiosas, políticas, comerciales...- más hechiceras, más engañosas y que tienden a confundir incluso a los más auditorios más lúcidos. Pero como es inútil combatir en general la dimensión expresiva del lenguaje - - s una dimensión inevitable-- de lo que se trata es de usar con legitimidad las artes de su eficacia: hay que hacer de la retórica un arte de la sabiduría ilustrada, no un "vicio republicano", sino un genuino «arte republicano». De ahí que, específicamente con respecto a la eficacia argumental, más que de una retórica, o quizá, junto a una retórica, se necesita una ética de la argumentación, una ética que, entre otras funciones, oriente para examinar y juzgar el poder de las palabras en relación con la autonomía personal y social: cuándo la dimensión expresiva de nuestros argumentos convence con legitimidad, y cuándo, sólo seduce al juicio. 